programmes that will prevent needless suffering in travellers and so help increase international trade and tourism.

Myron G Schultz

Centres for Disease Control,

US Department of Health and Human Services,

Atlanta,

Georgia 30333

USA

${ }^{1}$ Kendrick MA. Study of illness among Americans returning from international travel, July 11 -August 24 , preliminary data. $\mathcal{F}$ Infect $D$ is $1972 ; 126: 684-5$.

${ }^{2}$ Steffen R, van der Linde F, Meyer HE. Risk of illness among 10500 tourists from the tropics and 1300 tourists from North America. Schweiz Med Wochenschr 1978;108:1485-95. (In German.)

${ }^{3}$ Friel JP, ed. Dorland's illustrated medical dictionary. 26th edn. Philadelphia : Saunders, $1981: 435$.

4 Mackay DM. The British citizen abroad. Trans $R$ Soc Trop Med Hyg 1981 ;75, suppl: 45-6.

${ }^{5}$ Bruce-Chwatt LJ. Imported malaria: an uninvited guest. $\mathrm{Br}$ Med Bull $1982 ; 38: 179-85$

${ }^{6}$ Haworth J. Travel and health. World Health 1982;April:3-5.

\section{Preterm rupture of the membranes}

In between $6 \%$ and $12 \%$ of pregnancies ${ }^{1}$ the fetal membranes rupture spontaneously before labour begins-a condition still (rather unsatisfactorily) called "premature" rupture of the membranes. If the pregnancy is at term labour usually follows or is induced with oxytocin to avoid possible infection. In about $2-3 \%$ of pregnancies, however, the membranes rupture before 37 weeks' gestation. ${ }^{2}$ This condition is best called "preterm" rupture of the membranes ${ }^{13}$ : it occurs in around one-third of all preterm deliveries, ${ }^{2}$ and its management raises difficult questions.

Usually no cause can be found, but a few cases are due to trauma, hydramnios, or cervical incompetence. ${ }^{4}$ Normally the tensile strength of the membranes is higher in midpregnancy than at term ${ }^{56}$ : some investigators ${ }^{5}$ have reported an abnormally low collagen content in membranes that rupture spontaneously before term, but others ${ }^{6}$ have found no such abnormality and suggest that the rupture is due to localised weakness. Infection might be a cause, ${ }^{7}$ since amnionitis is more frequent ${ }^{4}$ when the membranes rupture just before labour than when they rupture just after its onset, ${ }^{4}$ and because preterm rupture of the membranes is more common $^{8}$ when there is vaginal colonisation with group B streptococci.

Diagnosis ${ }^{9}$ is usually based on the history, the results of examination with a sterile speculum (not digitally), and possibly testing the pool of liquid in the vagina with nitrazine. Urinary incontinence may be distinguished by giving the woman oral phenazopyridine to stain the urine. In the few cases $^{10}$ in which the diagnosis is still not clear staining of the amniotic fluid by amniocentesis has been suggested, ${ }^{910}$ but the risks include adverse effects of dye on the fetus, ${ }^{11}$ and most obstetricians would prefer to avoid this investigation.

Management presents the two problems of avoiding infection and minimising the risks of prematurity. A recent study in Oxford showed bacterial colonisation in $41 \%$ of neonates after preterm rupture of the membranes, compared with $28 \%$ after premature rupture of the membranes at term and $23 \%$ of term infants after elective amniotomy. ${ }^{2}$ Bacterial colonisation correlated poorly, however, with chorioamnionitis.
Seven of the 42 preterm infants in this survey died, but only one death was associated with septicaemia, the rest being due to complications of prematurity. The authors concluded that the major risk to the neonate in these cases is not infection but preterm delivery. The same conclusion has been reached elsewhere, ${ }^{212-15}$ and the evidence justifies the current trend towards conservative treatment. ${ }^{16}$ Furthermore, the risk of amnionitis does not increase with the passage of time after rupture of the membranes ${ }^{13}$ (at least among preterm pregnancies ${ }^{17}$ ). In one American study ${ }^{9}$ of 188 patients with premature rupture of the membranes treated conservatively there were no neonatal deaths from sepsis even though $19 \%$ of the patients went beyond seven days before labour began. In another study ${ }^{18}$ of 116 patients with preterm rupture the incidence of amnionitis before labour was 5\% and of neonatal sepsis $7 \%$; three babies died from prematurity and one fetal death was associated with infection.

How might the risk of infection be reduced? Prophylactic antibiotics are not helpful. ${ }^{1219}$ One of the most dangerous pathogens is the group B beta-haemolytic streptococcus. ${ }^{18}$ Carriers can be identified by vaginal ${ }^{20}$ or rectal ${ }^{21}$ cultures, allowing antibiotic treatment to be directed only at high-risk cases $^{14}{ }^{20}$-though there is no evidence ${ }^{22}$ that treating the mother prevents infection of the neonate. Another approach is to look for early signs of infection by changes in maternal serum. The concentration of C-reactive protein rises at least 12 hours before other signs of infection appear ${ }^{23}$ and may therefore warn that prompt delivery is indicated. Serum complement activity is low among patients with preterm rupture of the membranes compared with normal pregnant women (possibly because complement is consumed by subclinical infection), ${ }^{24}$ but it is not yet known whether very low complement values can accurately predict amnionitis.

Several reports ${ }^{14} \downarrow 15$ have suggested that respiratory distress syndrome becomes less likely the longer delivery is delayed after the membranes rupture, but other studies ${ }^{13} 2526$ have found that rupture of the membranes itself does not accelerate maturation of the lung. There seems no basis ${ }^{9}$ for fears that giving steroids to stimulate production of surfactant might increase the risk of infection, and a study ${ }^{27}$ of immunoglobulins in the cord blood has suggested that treatment with steroids does not interfere with the fetal humoral response. Steroids have to be given at least 24 hours before delivery to have any useful effects, and treatment with ritodrine to diminish uterine contractions may delay labour for 24 hours $^{14}$ despite the presence of ruptured membranes-though there is no evidence that ritodrine is effective for more than 24 hours in these circumstances or that such "tocolytic" treatment alone reduces the incidence of respiratory distress. The effectiveness of treatment with steroids may sometimes be monitored by estimating the lecithin:sphingomyelin ratio $^{28}$ or the phosphatidylglycerol content ${ }^{29}$ of the fluid draining from the vagina (provided contamination with maternal urine is avoided ${ }^{28}$ ); otherwise some obstetricians recommend amniocentesis, ${ }^{317} 30$ though theoretically this might increase the risk of infection. ${ }^{19}$ Reports ${ }^{25}$ that caesarean section increases the risk of respiratory distress have recently been disputed, ${ }^{26}$ and if delivery of a very premature baby becomes inevitable avoiding a potentially traumatic vaginal delivery ${ }^{31}$ may increase the infant's chances of survival.

JAMES OWEN DRIFE

Lecturer in Obstetrics and Gynaecology,

Bristol Maternity Hospital,

Bristol BS2 8EG

${ }^{1}$ Anonymous. Premature rupture of the membranes. $\operatorname{Br} \operatorname{Med} \mathcal{f} 1979$;i: $1165-6$. 
${ }^{2}$ Zaaijman JduT, Wilkinson AR, Keeling JW, Mitchell RG, Turnbull AC. Spontaneous premature rupture of the membranes: bacteriology, histology and neonatal outcome. Fournal of Obstetrics and Gynaecology $1982 ; 2: 155-60$.

${ }^{3}$ Rush RW. The management of preterm rupture of the membranes. $S$ Afr Med f 1980;58:690-1.

${ }^{4}$ Naeye RL, Peters EC. Causes and consequences of premature rupture of fetal membranes. Lancet $1980 ; \mathrm{i}: 192-4$.

${ }^{5}$ Skinner SJM, Campos GA, Liggins GC. Collagen content of human amniotic membranes: effect of gestation length and premature rupture. Obstet Gynecol $1981 ; 57: 487-9$.

6 Al-Zaid NS, Bou-Resli MN, Goldspink G. Bursting pressure and collagen content of fetal membranes and their relation to premature rupture of the membranes. Br $\mathcal{F}$ Obstet Gynaecol 1980;87:227-9.

${ }^{7}$ Creatsas G, Pavlatos M, Lolis D, Aravantinos D, Kaskarelis D. Bacterial contamination of the cervix and premature rupture of membranes. Am $\mathcal{F}$ Obstet Gynecol 1981;139:522-5.

${ }^{8}$ Regan JA, Chao S, James LS. Premature rupture of membranes, preterm delivery, and group B streptococcal colonization of mothers. $A m \mathcal{F}$ Obstet Gynecol 1981;141:184-6.

${ }^{9}$ Kappy KA, Cetrulo CL, Knuppel RA, et al. Premature rupture of the membranes: a conservative approach. Am $\mathcal{F}$ Obstet Gynecol 1979;134: 655-61.

10 Smith RP. A technic for the detection of rupture of the membranes. Obstet Gynecol 1976;48:172-6.

11 Serota FT, Bernbaum JC, Schwartz E. The methylene-blue baby. Lancet 1979;ii:1142-3.

12 Daikoku NH, Kaltreider F, Johnson TRB Jr, Johnson JWC, Simmons MA. Premature rupture of membranes and preterm labor: neonatal infection and perinatal mortality risks. Obstet Gynecol $1981 ; 58: 417-25$.

${ }^{13}$ Schreiber J, Benedetti T. Conservative management of preterm premature rupture of the fetal membranes in a low socioeconomic population. Am $\mathcal{F}$ Obstet Gynecol 1980;136:92-6.

${ }^{14}$ Christensen KK, Ingemarsson I, Leideman $T$, Solum $H$, Svenningsen $N$. Effect of ritodrine on labor after premature rupture of the membranes. Obstet Gynecol 1980;55:187-90.

15 Berkowitz RL, Bonta BW, Warshaw JE. The relationship between premature rupture of the membranes and the respiratory distress syndrome. Am f Obstet Gynecol 1976;124:712-8.

${ }^{16}$ Chance GW. Elective delivery, premature rupture of the membranes and the respiratory distress syndrome. Can Med Assoc f 1980;122:265-7.

${ }^{17}$ Mead PB. Management of the patient with premature rupture of the membranes. Clin Perinatol 1980;7:243-55.

18 Varner MW, Galask RP. Conservative management of premature rupture of the membranes. Am $\mathcal{F}$ Obstet Gynecol 1981;140:39-43.

${ }^{19}$ Zaaijman JduT. Spontaneous premature rupture of the fetal membranes. $S$ Afr Med F 1980;58:345-6.

${ }^{20}$ Pasnick M, Mead PB, Philip AGS. Selective maternal culturing to identify group B streptococcal infection. Am f Obstet Gynecol 1980; 138:480-4.

${ }^{21}$ Anthony BF, Eisenstadt R, Carter J, Kim KS, Hobel CJ. Genital and intestinal carriage of group B streptococci during pregnancy. $\mathcal{F}$ Infect Dis $1981 ; 143: 761-6$

22 Varner MW, Pitkin RM. Editorial comment. Obstet Gynecol Surv 1982; 37:174-5.

${ }^{23}$ Evans MI, Haji SN, Devoe LD, Angerman NS, Moawad AH. C-reactive protein as a predictor of infectious morbidity with premature rupture of the membranes. Am $\mathcal{F}$ Obstet Gynecol 1980;138:648-52.

${ }^{24}$ Levy DL, Arquembourg PC. Maternal and cord blood complement activity: relationship to premature rupture of the membranes. $A m \mathcal{F}$ Obstet Gynecol 1981;139:38-40.

${ }^{25}$ Jones MD Jr, Burd LI, Bowes WA Jr, Battaglia FC, Lubchenco LO. Failure of association of premature rupture of membranes with respiratory-distress syndrome. N Engl f Med 1975;292:1253-7.

${ }^{26}$ Papageorgiou AN, Colle E, Farri-Kostopoulos E, Gelfand MM. Incidence of respiratory distress syndrome following antenatal betamethasone role of sex, type of delivery, and prolonged rupture of membranes. Pediatrics 1981;67:614-7.

${ }^{27}$ Cederqvist LL, Ekelund L, Litwin SD. Effect of glucocorticoids on fetal immunoglobulin production after premature rupture of membranes. Obstet Gynecol 1980;55:444-6.

${ }^{28}$ Isherwood DM, McMurray JA, Campbell C, Jenkins DM. Prediction of fetal pulmonary maturity from amniotic fluid obtained from the vagina after premature rupture of the membranes. A patient treated with dexamethasone. Acta $\odot$ bstet Gynecol Scand 1981;60:83-5.

${ }^{29}$ Stedman CM, Crawford S, Staten E, Cherny WB. Management of preterm premature rupture of membranes: assessing amniotic fluid in the vagina for phosphatidylglycerol. Am F Obstet Gynecol 1981;140:34-8.

${ }^{30}$ Le Guennec JC, Bard H, Teasdale F, Doray B. Elective delivery and the neonatal respiratory distress syndrome. Can Med Assoc $\mathcal{F} 1980 ; 122$ : 307-9.

31 Nochimson DJ, Petrie RH, Shah BL, Pampati N, Brunelle D. Comparison of conservative and dynamic management of premature rupture of membranes/premature labor syndrome. New approaches to the delivery of infants which may minimize the need for intensive care. Clin Perinatol $1980 ; 7: 17-31$

\section{Ketoconazole}

Ketoconazole, one of the newer imidazole antifungal agents, is potentially the most useful derivative to date since it can be given by mouth. In vitro it has a broad spectrum of antifungal activity ranging from Candida species and dermatophytes to systemic pathogenic fungi such as Histoplasma capsulatum. Some moulds, including aspergilli, are inhibited only at high concentrations. Ketoconazole appears to act by inhibiting the conversion of lanosterol into ergosterol in the cell wall, though other mechanisms may also play some part. In man peak serum concentrations of $2-5 \mathrm{mg} / 1$ are found two to three hours after administration of a single $200-\mathrm{mg}$ tablet. ${ }^{1}$ Therapeutic serum concentrations do not usually persist longer than eight hours unless a high dose, over $800 \mathrm{mg}$, is given. Absorption is enhanced in the presence of acid, but whether or not concurrent administration of antacids inhibits uptake is not yet clear. ${ }^{2}$ The drug is metabolised in the liver, but peak serum concentrations do not appear to be greatly altered in the presence of liver disease. Ketoconazole penetrates the cerebrospinal fluid and the peritoneal cavity in low concentrations, and less than $13 \%$ of the absorbed dose is excreted in the urine.

Ketoconazole has been used most widely in the treatment of superficial mycoses such as dermatophytosis and candidiasis. In the former there is good evidence that ketoconazole is effective; for instance, in one open study ${ }^{3}$ the investigators showed that $90 \%$ of treated patients were improved, particularly when the infection was confined to hairless skin. Three-quarters of the treated patients relapsed within five months of stopping ketoconazole, however, and the effect of the drug on nail infections was not assessed. Onchomycosis caused by dermatophytes can also be successfully treated, though toenail infections in particular are slow to respond and may be refractory to treatment. In one double-blind comparative study ${ }^{4}$ of ketoconazole $(200 \mathrm{mg})$ and griseofulvin (250 mg ultramicrosize) clinical remissions were induced in $61 \%$ and $39 \%$ of treated cases respectively. Up till now most investigators have studied broad groups of dermatophyte infections, and it would be most helpful to substantiate these observations in specific forms of dermatophytosis such as tinea capitis.

The value of ketoconazole in chronic mucocutaneous candidiasis has been established in several studies, including one placebo-controlled trial. ${ }^{5} \mathrm{~A}$ substantial proportion of treated patients with chronic mucocutaneous candidiasis achieve complete mycological and clinical'remission. In one study six out of 17 patients relapsed with oral infection within 8.4 months of stopping the drug but responded to retreatment. ${ }^{6}$ These results in an infection such as chronic mucocutaneous candidiasis are encouraging and hold out hope that similar persistent infections will respond as well. Ketoconazole is active against vaginal candidiasis and is likely to prove more acceptable to patients than topical treatment. As even short regimens of topical drugs have proved to be highly effective, however, the comparative merits of ketoconazole need to be carefully assessed.

Few reports have appeared of the use of ketoconazole in the subcutaneous mycoses, though some therapeutic effect has been described in chromomycosis. ${ }^{1}$ Some of the systemic mycoses, however, particularly certain forms of paracoccidioidomycosis, ${ }^{7}$ respond dramatically to the drug. Some clinical varieties of coccidioidomycosis and histoplasmosis may also respond. ${ }^{1}$

As yet the value of katoconazole cannot be assessed in opportunistic fungal infections such as systemic candidiasis or 